\title{
Waveguide Applicator System for Head and Neck Hyperthermia Treatment
}

\author{
Ondrej Fiser ${ }^{\dagger}$, Ilja Merunka* and Jan Vrba*
}

\begin{abstract}
The main purpose of this article is a complex hyperthermia applicator system design for treatment of head and neck region. The applicator system is composed of four waveguides with a stripline horn aperture and circular water bolus. The specific absorption rate (SAR) and temperature distribution from this applicator in various numerical phantom models was investigated. For used targets, the treatment planning based on the optimization process made through the SEMCAD X software is added to show the steering possibilities of SAR and thereby temperature distribution. Using treatment planning software, we proved that the SAR and temperature distribution can be effectively controlled (by amplitude and phase changing) improving the SAR and temperature target coverage approximately by $20 \%$. For the proposed applicator system analysis and quantitative evaluation of two parameters $25 \%$ iso-SAR and $41^{\circ} \mathrm{C}$ iso-temperature contours in the treatment area with the respect to sensitive structures in treatment area were defined. To verify our simulation results, the real measurement of reflectivity coefficient as well as the temperature distribution in a homogenous phantom were performed.
\end{abstract}

Keywords: Head and neck cancer, Hyperthermia system, Hyperthermia treatment, Oncology, Phased array

\section{Introduction}

Head and neck cancer is the sixth most common cancer type in the European Union [1]. This is due to smoking and excessive alcohol consumption [1]. Other carcinogens causing cancer in head and neck region are human papillomavirus (HPV) and Epstein-Barr virus (EBV) [1], [2]. The frequently occurring head and neck cancers, which are appropriate for microwave hyperthermia treatment, are tumors of the vocal cords, thyroid gland and adjacent lymph nodes [2]. Curability depends on used frequency and depth of the tumor under the skin [3]. The clinical trials (phase III) show that a combination of hyperthermia treatment, radiotherapy [4] and chemotherapy [5] improves the survival chance of patients with head and neck tumors [6,7] and [8]. Microwave hyperthermia belongs to nontoxic oncological treatment using frequencies 60120, 434 and $915 \mathrm{MHz}[3,9]$ and [10]. The goal of the hyperthermia treatment is to achieve a temperature range of $41-45^{\circ} \mathrm{C}$ (for $40-90 \mathrm{~min}$ or longer) in tumor tissue [3, 11] and [12]. This temperature leads to tumor cell apoptosis or it can cause greater cell sensitivity to ionizing radiation [3].

To improve treatment of malignant tumors in relatively complicated head and neck region, a semicircle applicator

\footnotetext{
$\dagger \quad$ Corresponding Author: Dept. of Electromagnetic Field, Czech Technical University in Prague, Czech Republic. (fiseron2@fel.cvut.cz)

* Dept. of Electromagnetic Field, Czech Technical University in Prague, Czech Republic

Received: July 6, 2015 ; Accepted: April 27, 2016
}

system composed of four equal waveguide applicators was designed. In case of the using multiple coherent applicators utilization, it is needful to plan the treatment through the optimization of specific absorption rate (SAR) distribution [13] for each particular specific patient case. As we know, some circular phase array systems intended for head and neck hyperthermia treatment are currently under development (e.g. Paulides et al. (2007) [6] and Trefna et al. (2010) [14]).

The main purpose of this article is to introduce and show specific advantages of a novel approach of hyperthermia treatment in head and neck region. We numerically and experimentally evaluated the microwave focusing to targets of various sizes. As a suitable working frequency with the respect to the SAR steering ability in head and neck region, the frequency of $434 \mathrm{MHz}$ was chosen.

\section{Waveguide Applicator Description}

The presented applicator system is composed of four waveguide applicators. The advantage of the waveguide type applicator is the ability to transfer maximum energy without energy losses and without irradiation to the surrounding area [15, 16] and [17]. The mentioned waveguide applicator is designed for local hyperthermia treatment. In order to minimize the dimensions of the whole applicator, the waveguide is filled with distilled water and is terminated by a strip line horn aperture. The reason and purpose of dielectric sidewalls (strip-line 
Table 1. Waveguide dimensions (see symbols in the Fig. 1 a)

\begin{tabular}{c|c}
\hline Symbol & Dimensions $[\mathrm{mm}]$ \\
\hline $\mathrm{L}_{\mathrm{a}}$ & 50 \\
\hline $\mathrm{L}_{\mathrm{b}}$ & 50 \\
\hline $\mathrm{a}$ & 58 \\
\hline $\mathrm{b}$ & 29 \\
\hline $\mathrm{A}$ & 100 \\
\hline $\mathrm{B}$ & 50 \\
\hline
\end{tabular}

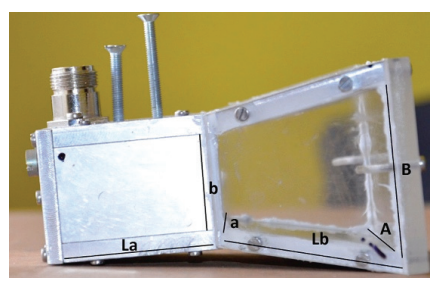

(a)

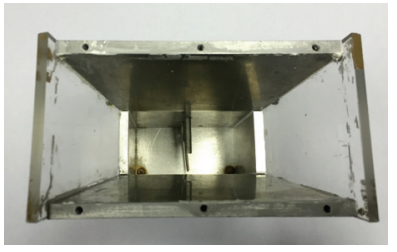

(b)

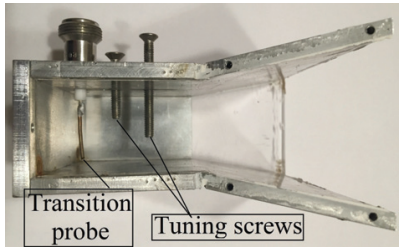

(c)
Fig. 1. Waveguide applicator with dimension symbols: (a), applicator from the front; (b) and detail of applicator feeding with tuning screws (c)

aperture) is to increase the effective aperture and field homogeneity in front of the applicator. The described applicator is in the Fig. 1(a) side view, (b) front view and (c) detail of applicator feeding with tuning screws). The applicator operates on frequency $434 \mathrm{MHz}$.

The material used for the waveguide applicator is aluminum while the sidewalls of the stripline horn are made with acrylic glass. The dimensions of the waveguide are designed for excitation of the dominant mode $\mathrm{TE}_{10}$ at working frequency (see Table 1). To match the applicator impedance to the coaxial cable and phantom, two impedance transformers at a distance of $\lambda / 4$ and $\lambda / 8$ (where $\lambda$ is wavelength in waveguide) from the coaxial waveguide transition probe are placed. Thanks to that we are able to have applicator adaptability for all types of phantoms.

\section{Applicators Configuration}

We studied the amplitude and phase impact of used waveguide applicators on the electromagnetic field stratification, cf. our previous research (published in [15, 16] and [17]). A higher number of applicators, e.g. 7 (analyzed in [17]), led to the creation of unwanted hotspots close to sensitive tissues (e.g. spinal cord and

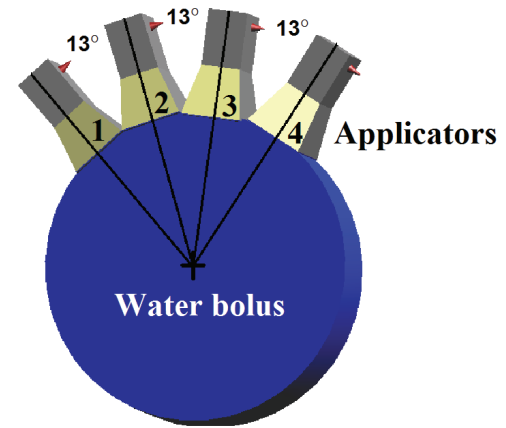

Fig. 2. Applicator system setup with water bolus

brain tissue). Therefore we redesigned the applicator system by reducing the number of applicators (from seven to four). This modification led to lower hotspot formation risk but approximately $12 \%$ reduction of target coverage. This new applicator system is composed of four waveguide applicators. The applicators-phantom distance is $77 \mathrm{~mm}$. This distance maintains relatively high sensitivity for field steering by phase and amplitude changing. Applicators array can be rotated around the patient's head and neck for optimal position and ideal coverage of the treated tissue by the electromagnetic power, and subsequently by temperature. The angle among applicators is 13 degrees (see Fig. 2). The penetration depth of all four applicators (in case of same amplitude and phase excitation) is $4.8 \mathrm{~cm}$ corresponding to $75 \%$ decrease of maximum SAR. For comparison: one single applicator is of $2.4 \mathrm{~cm}$ penetration depth only. The applicator setup with water bolus is obvious from Fig. 2.

\section{Water Bolus}

Between patient and applicators, a circular water bolus is placed. Fig. 2 shows the applicator system with circular water bolus which is filled with distilled water (tempered to constant temperature $21^{\circ} \mathrm{C}$ ). The water bolus plays two substantial roles. The first one is to cool the patient's skin, through this avoiding hot spot formation. The second one is a coupling media between applicator and phantom. Circular water bolus is of $380 \mathrm{~mm}$ in diameter and $200 \mathrm{~mm}$ in height. Size and shape of the water bolus is affecting two important system parameters-namely impedance matching and field homogeneity.

\section{Numerical Phantoms}

For the design and testing of an applicator system, three numerical phantoms were used. Within these phantoms, the ability of electromagnetic field focusing into various treatment targets and consequently temperature distribution was studied. Dielectric and thermal parameters of all phantoms were taken from the IT'IS foundation materials 
Table 2. Targets volume summary

\begin{tabular}{c|c|c}
\hline \multicolumn{2}{|c|}{ Target } & Volume $\left[\mathrm{cm}^{3}\right]$ \\
\hline 1 & Tumor I & 12.5 \\
\hline 2 & Tumor II & 16.4 \\
\hline 3 & Thyroid gland & 10.6 \\
\hline 4 & Tongue & 60.6 \\
\hline 5 & Tumor III & 246 \\
\hline
\end{tabular}

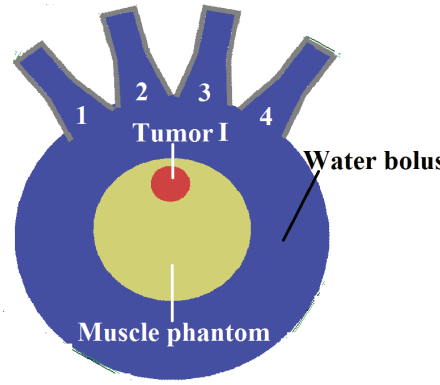

(a)

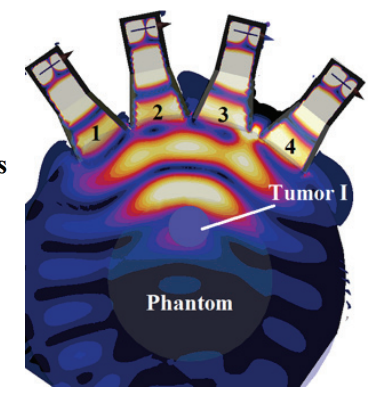

(b)
Fig. 3. Homogenous phantom cross-section with applicator array: (a) and real modulus of E-field (b)

database [18] while the working frequency is being 434 MHz. In the Table 2, the summarizing information of targets volume is shown. To meet input parameters read Table 3 .

\subsection{Homogenous phantom}

Homogenous phantom was used for the applicator position proposal i.e. the applicator-phantom distance determination, shape of the water bolus with the respect to the best possible field steering sensitivity. The circular homogenous phantom is composed of 2 different parts.

Dimensions of heterogeneous phantom are $160 \mathrm{~mm}$ in diameter and $100 \mathrm{~mm}$ in height. In phantom an artificial cylindrical tumor $(20 \mathrm{~mm}$ in diameter $)$ is placed $10 \mathrm{~mm}$ under the surface. In the Fig. 3 (a) there is the cross section of the system with homogenous phantom and the Fig. 3 (b) the distribution of E-field in water bolus and phantom with no optimization is shown.

\subsection{Human model Ella}

We used "human model part" of the SEMCAD X models database [18]. For our purposes, the human model with name Ella from Virtual Family 1.2 was utilized. Around the neck we placed proposed applicator system with water bolus. Using this numerical model we choose three different targets:

- Thyroid gland

- Tongue

- Tumor II (18 mm under skin)

Each target has a specific shape and position (see Fig. 4

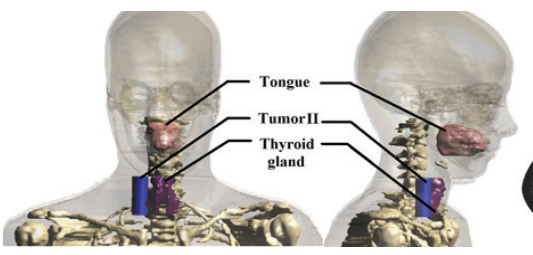

(a)

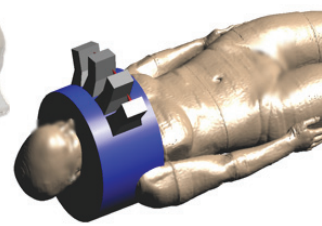

(b)
Fig. 4. Numerical Human model Ella: (a) targets and (b) applicators position (a)

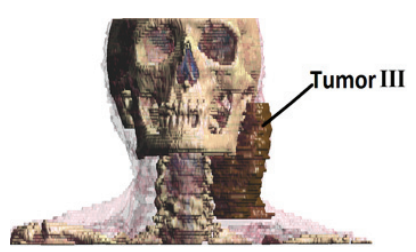

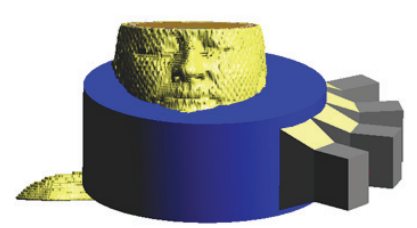

(b)
Fig. 5. Numerical model of real patient with tumor: (a) and applicators configuration (b)

(a). The detail of the array localization is obvious from Fig. 4 (b).

\subsection{Real Patient Model}

The function of our proposed array of applicators we verified using the model of a real patient that was adopted from [19]. The volume and size of tumor is so large that it cannot be appropriately covered by a single aperture only [17]. Our proposed applicator system is more convenient to be used in this case. The $3 \mathrm{D}$ numerical patient model was reconstructed from CT scans by semi-automatic segmentation toolbox iSeq integrated in SEMCAD X. In the Fig. 5 (a), the resulting numerical model is shown. Fig. 5 (b) shows the placement applicator system around the patient's neck. Against applicator positions in Fig. 4 (b) all applicators are rotated by 40 degrees to show positioning options of heating system.

\section{Simulation and SAR Optimization}

The effectiveness of the new applicator system is shown through the SAR and temperature distribution calculated by SEMCAD X 14.8 [20]. SAR distribution is useful especially for technical development and comparison of the discussed applicator system. From a clinical point of view it is better to utilize the temperature simulations. The thermal simulation keeps us informed about temperature distribution. The temperature simulation enables us to consider parameters like thermal conduction, blood perfusion and bolus cooling.

Two parameters $\mathrm{SAR}_{25}$ and $\mathrm{T}_{41}$ are used for the evaluation of gained results. $\mathrm{SAR}_{25}$ is related to absorption 
energy and $\mathrm{T}_{41}$ is related to temperature distribution. $\mathrm{SAR}_{25}$ is a volume where the SAR is greater than $25 \%$ of its maximum in the considered target (according to the Eq. 1). $\mathrm{T}_{41}$ is the volume of temperature $41-45{ }^{\circ} \mathrm{C}$ in the heated target (Eq. 2).

$$
S A R_{25}[\%]=\frac{V_{t \arg e t}\left(S A R>S A R_{\max } \cdot 0.25\right)}{V_{t \arg e t}} \cdot 100 \%
$$

where

$\mathrm{SAR}_{\max }$ is maximum SAR in the whole model and $\mathrm{V}_{\text {target }}$ is the volume of treated target.

$$
T_{41}[\%]=\frac{V_{t \arg e t}\left(T>41^{\circ} C\right)}{T_{t \arg e t}} \cdot 100 \%
$$

where

$\mathrm{T}$ is temperature.

\subsection{Treatment planning (SAR optimization)}

Hyperthermia treatment planning is necessary activity improving the quality of the hyperthermia treatment (similarly like in radiotherapy). For more complex system composed of more than one applicator (like our applicator system) it is desirable to perform treatment planning with field optimization. The planning system predicts the SAR and temperature distribution in the patient, optimizes the system properties and through this it improves energy delivery to the tumor, reduces healthy tissue hotspots, improves the quality and general success of the hyperthermia treatment. An optimized SAR distribution can be reached by tuning the phase and amplitude of the applicator. For evaluation of our system, the planning software (SAR optimizer) as a part of simulator EM-field
SEMCAD X based on Genetic algorithm was used. The optimization process is based on the following cost function $L$ (3) adopted from [20]:

$$
L=\frac{\int_{t \arg e t} w(x, y, z) \cdot \operatorname{SAR}(x, y, z) d V}{\int_{\text {all-t } \operatorname{targ} e t} w(x, y, z) \cdot \operatorname{SAR}(x, y, z) d V}
$$

where $\mathrm{w}(\mathrm{x}, \mathrm{y}, \mathrm{z})$ is a weighting parameter. The weighting function $\mathrm{w}$ determines the priority and sensitivity of target against the whole phantom volume. The algorithm is searching for maximum of used cost function $L$.

\subsection{Thermal simulation}

SEMCAD X simulator is also appropriate for thermal simulations [20]. Thermal solver uses results from the optimized SAR distribution as a heat source through Penne's Bioheat equation. In the beginning of heating, all tissue temperatures were set to $37{ }^{\circ} \mathrm{C}$ and the temperature of water bolus was set to $25{ }^{\circ} \mathrm{C}$. The value of the heat transfer coefficient between human body and circulated water was set to $65 \mathrm{~W} / \mathrm{m}^{2} / \mathrm{K}[21]$. Within the results of temperature distribution, the $41^{\circ} \mathrm{C}$ iso-volume is marked (like lower limit of treatable temperature).

Temperature parameters used in temperature calculations (Specific heat capacity, Thermal conductivity and Heat generation rate) are listed in Table 3. Blood circulation in arteries and veins are also involved in the calculations.

\section{Simulation Results}

In Fig. 6 and 7, the results from numerical simulations

\begin{tabular}{|c|c|c|c|c|c|}
\hline Material & $\begin{array}{c}\text { Relative permittivity } \varepsilon \\
{[-]}\end{array}$ & $\begin{array}{c}\text { Conductivity } \sigma \\
{[\mathbf{S} / \mathbf{m}]}\end{array}$ & $\begin{array}{c}\text { Specific Heat Capacity } \\
{[\mathrm{J} / \mathrm{kg} / \mathrm{K}]}\end{array}$ & $\begin{array}{c}\text { Thermal Conductivity } \\
{[\mathbf{W} / \mathbf{m} / \mathbf{K}]}\end{array}$ & $\begin{array}{c}\text { Heat Generation Rate } \\
{[\mathrm{W} / \mathrm{kg}]}\end{array}$ \\
\hline Artery & 61 & 1.58 & 3617 & 0.51 & - \\
\hline Bone & 13.1 & 0.09 & 1312 & 0.32 & 0.15 \\
\hline Water bolus & 81 & 0 & - & 0.56 & - \\
\hline Fat & 11.6 & 0.08 & 2348 & 0.21 & 0.51 \\
\hline Muscle & 56.9 & 0.79 & 3421 & 0.49 & 0.96 \\
\hline Skin & 40.9 & 0.89 & 3390 & 0.37 & 1.65 \\
\hline Tumor & 59.5 & 0.89 & 2654 & 0.27 & 1.53 \\
\hline Trachea & 43.9 & 0.8 & 3568 & 0.48 & 0.54 \\
\hline Thyroid gland & 61.3 & 0.97 & 3421 & 0.49 & 87.1 \\
\hline Esophagus & 64.8 & 1.23 & 3500 & 0.52 & 2.94 \\
\hline Vertebrae & 13.1 & 0.09 & 1312 & 0.32 & 0.15 \\
\hline Spinal cord & 32.2 & 0.59 & 3630 & 0.51 & 2.48 \\
\hline Larynx & 45.1 & 0.59 & 3568 & 0.48 & 0.54 \\
\hline Intervertebral disc & 45.1 & 0.59 & 3560 & 0.49 & 0.54 \\
\hline Vein & 61 & 1.59 & 3617 & 0.52 & - \\
\hline Cerebrospinal fluid & 70.6 & 2.25 & 4095 & 0.57 & - \\
\hline Connective tissue & 47.1 & 0.56 & 2372 & 0.39 & 0.58 \\
\hline Teeth & 13.1 & 0.09 & 1255 & 0.59 & - \\
\hline Nasal cavity & 45.71 & 0.88 & 3150 & 0.34 & - \\
\hline Tongue & 5.74 & 0.78 & 3568 & 0.49 & 1.21 \\
\hline
\end{tabular}

Table 3. Dielectric and thermal properties of numerical phantoms and parts of waveguide applicator for frequency 434 $\mathrm{MHz}$ [18] 
are presented. Using these results we investigate applicator system ability to focus the microwave energy to the treated

Table 4. Phase (P, degrees) and relative amplitude (A,-) setting for each applicator for all targets

\begin{tabular}{c|c|c|c|c|c|c|c|c}
\hline & \multicolumn{9}{|c|}{ Target } \\
\hline $\begin{array}{c}\text { Nr. } \\
\text { App }\end{array}$ & \multicolumn{2}{|c|}{ Tumor I } & \multicolumn{2}{c|}{ Tumor II } & \multicolumn{2}{c}{$\begin{array}{c}\text { Thyroid } \\
\text { gland }\end{array}$} & \multicolumn{2}{c}{ Tumor III } \\
\hline & A & P & A & P & A & P & A & P \\
\hline 1 & 0.39 & 0 & 0.87 & 0 & 1 & 0 & 0.41 & 0 \\
\hline 2 & 1 & -56.3 & 0.93 & -38.3 & 0.83 & 64.9 & 1 & -69.2 \\
\hline 3 & 0.82 & -70.7 & 1 & -0.6 & 0.88 & 8.47 & 0.99 & -59.3 \\
\hline 4 & 0.55 & -6.5 & 0.87 & -8.7 & 0.98 & 42.4 & 0.64 & -67.8 \\
\hline
\end{tabular}

Predicted SAR distribution

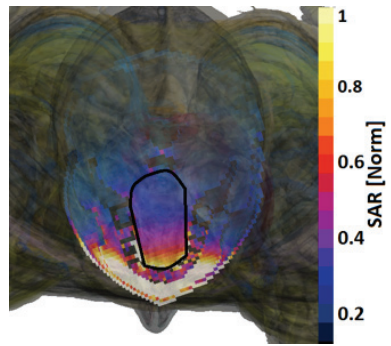

$\left(a_{1}\right)$

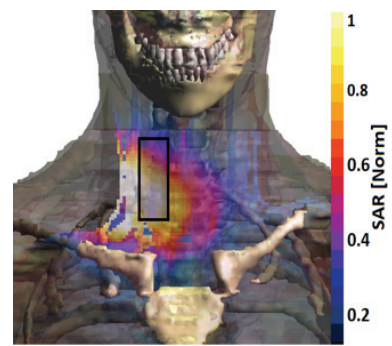

$\left(b_{1}\right)$

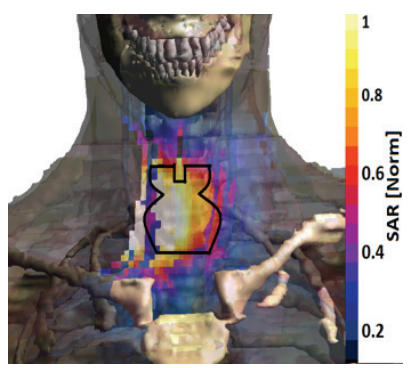

$\left(c_{1}\right)$

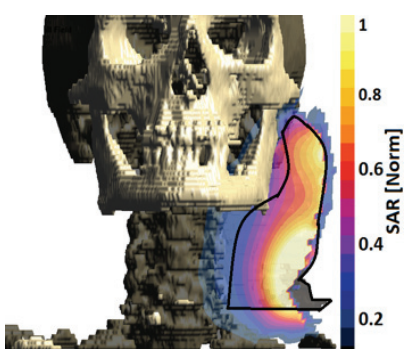

$\left(\mathrm{d}_{1}\right)$

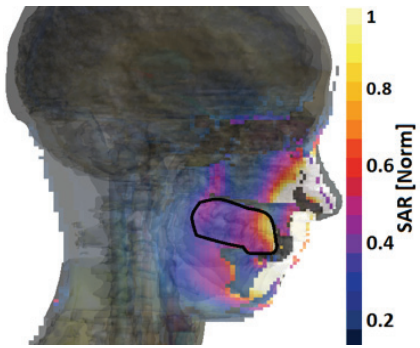

$\left(\mathrm{a}_{2}\right)$

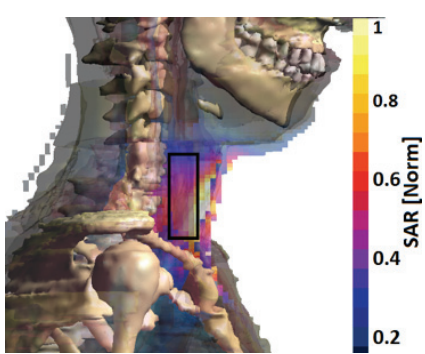

$\left(b_{2}\right)$

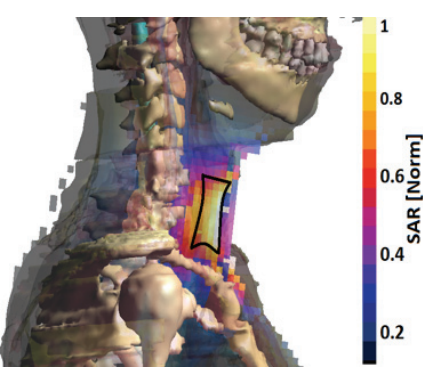

$\left(c_{2}\right)$

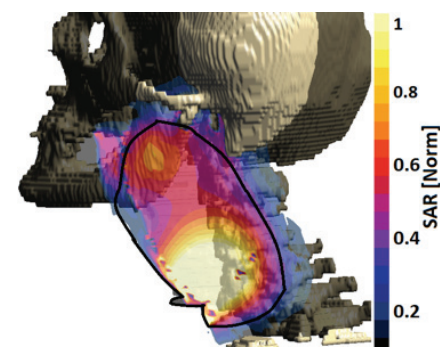

$\left(d_{2}\right)$

target. This energy is manifested by temperature increasing. In Fig. 6, the phantom SAR distribution is shown in the first and second columns. The third and fourth columns show us the $\mathrm{T}_{41}$ iso-volume contour coverage. In all cases the output power of each applicator was set in order not to exceed the $45{ }^{\circ} \mathrm{C}$ temperature maximum in the whole phantom. Fig. 6 a) demonstrates tongue, b) tumor II, c) thyroid gland and d) tumor III, all as for the treated area. For easier comparison all SAR values shown in figures are normalized to total input power $1 \mathrm{~W}$. In the Fig. 7 there is a SAR-Volume histogram of targets coverage. This figure is obtained from optimized SAR simulations and is used to determine the value of $\mathrm{SAR}_{25}$ volume cover. The dashed

Predicted $\mathrm{T}_{41}$ Iso-temperature volumes

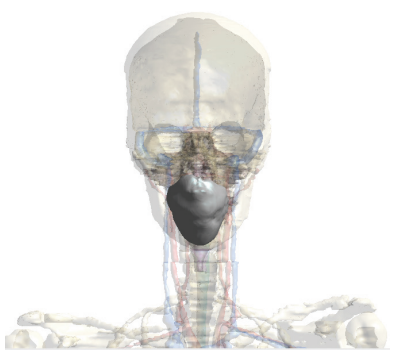

$\left(\mathrm{a}_{3}\right)$

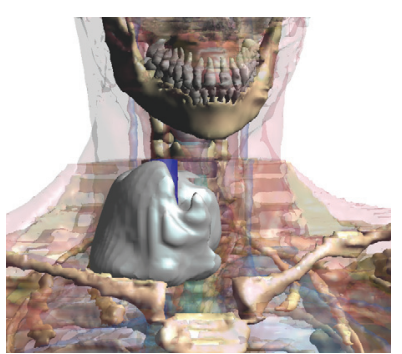

$\left(b_{3}\right)$

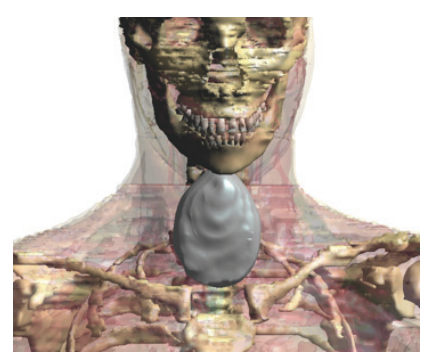

$\left(c_{3}\right)$

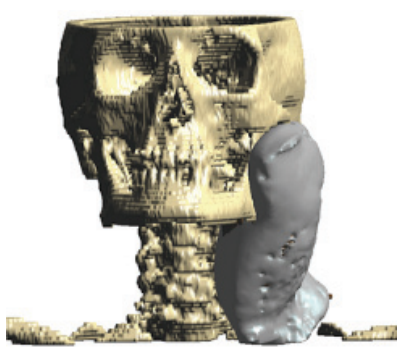

$\left(d_{3}\right)$

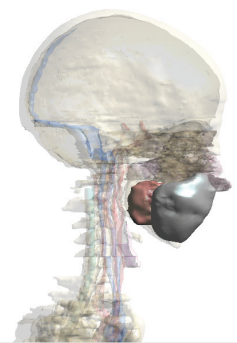

$\left(a_{4}\right)$

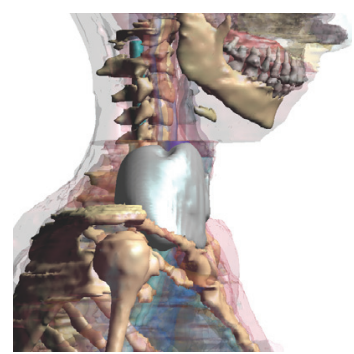

$\left(b_{4}\right)$

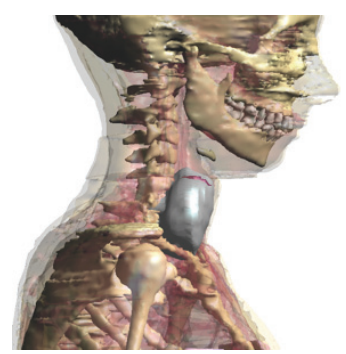

$\left(c_{4}\right)$

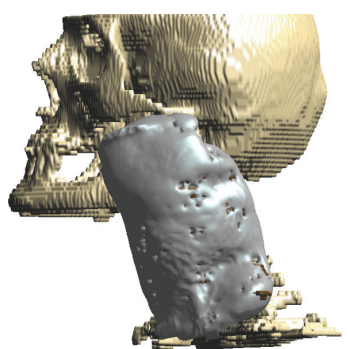

$\left(\mathrm{d}_{4}\right)$

Fig. 6. Optimized SAR distribution in transversal (index 1), longitudinal cross sections (index 2) and temperature isosurface $\mathrm{T}_{41}$ (index 3 and 4); tongue (a), tumor (b), thyroid gland (c) and real tumor (d) 


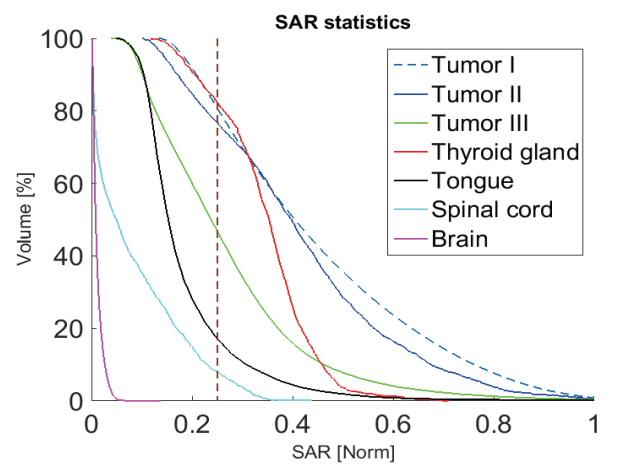

Fig. 7. Cumulative optimized SAR histogram

Table 5. $\mathrm{SAR}_{25}$ and $\mathrm{T}_{41}$ iso-contour target volume coverage

\begin{tabular}{c|c|c|c}
\hline Target & $\begin{array}{c}\mathrm{SAR}_{25} \\
{[\%]}\end{array}$ & $\begin{array}{c}\mathrm{T}_{41} \\
{[\%]}\end{array}$ & $\begin{array}{c}\text { No optimized } \\
\mathrm{SAR}_{25}[\%]\end{array}$ \\
\hline Tumor I & 85 & 95 & 70 \\
\hline Tumor II & 80 & 90 & 58 \\
\hline Thyroid gland & 87 & 92 & 75 \\
\hline Tongue & 21 & 51 & 6 \\
\hline Tumor III & 54 & 80 & 36 \\
\hline
\end{tabular}

vertical line indicates the value of $25 \%$ residual SAR. The light blue curve corresponds to SAR distribution in the spinal cord (temperature sensitive tissue).

In Table 5, target coverage is shown. The best cover results were achieved through Tumor I $\left(\mathrm{SAR}_{25} 85 \%\right.$ and $\left.\mathrm{T}_{41} 95 \%\right)$, Tumor II $\left(\mathrm{SAR}_{25} 80 \%\right.$ and $\left.\mathrm{T}_{41} 90 \%\right)$ and thyroid gland $\left(\mathrm{SAR}_{25} 87 \%\right.$ and $\left.\mathrm{T}_{41} 92 \%\right)$. On the contrary we did not achieve satisfactory SAR and temperature tongue cover $\left(\mathrm{SAR}_{25} 21 \%\right.$ and $\left.\mathrm{T}_{41} 51 \%\right)$. The applicator system is effective also for the larger tumor III $\left(\mathrm{SAR}_{25}\right.$ $54 \%$ and $\mathrm{T}_{41} 80 \%$ ). Because the tumor is located on the surface it is possible to use a higher power and cooler water bolus for good $\mathrm{T}_{41}$ coverage. In Table 4 the applicators settings for each target are listed. For comparison we added to Table $5 \mathrm{SAR}_{25}$ in the non-optimized case. One can see that the values are significantly lower. That means that the optimization increases the power concentration in the treated area.

\section{Measurement (Experiments)}

\subsection{Agar phantom for verification}

For measuring purposes, a cylindrical homogeneous (160 $\mathrm{mm}$ in diameter) phantom with an inserted cylindrical tumor (20 $\mathrm{mm}$ in diameter) was made. Phantom ingredients and their quantities are listed in the following Table 6. A completed phantom can be seen in Fig. 8 (a).

For determination of complex permittivity of a real agar phantom the method based on reflection coefficient measurement by coaxial probe was used [23]. This method is applicable in a frequency range from $30 \mathrm{MHz}$ to $1 \mathrm{GHz}$. The results of measurement are listed in Table 7.
Table 6. Ingredients quantity of healthy [3] and tumorous tissue phantom [22]

\begin{tabular}{c|c|c}
\hline Substance & $\begin{array}{c}\text { Healthy tissue } \\
{[\%]}\end{array}$ & $\begin{array}{c}\text { Tumorous tissue } \\
{[\%]}\end{array}$ \\
\hline Deionized water & 95 & 66 \\
\hline Agar & 4 & 3 \\
\hline $\mathrm{NaCl}$ & 0.35 & 0.5 \\
\hline Food color & 0.65 & 0.5 \\
\hline Ethanol & - & 30 \\
\hline
\end{tabular}

Table 7. Measured dielectric parameters of heterogeneous phantom for $434 \mathrm{MHz}$

\begin{tabular}{c|c|c}
\hline Type of tissue & $\begin{array}{c}\text { Relative permittivity } \\
{[-]}\end{array}$ & $\begin{array}{c}\text { Conductivity } \\
{[\mathrm{S} / \mathrm{m}]}\end{array}$ \\
\hline Muscle phantom & 60.79 & 0.58 \\
\hline Tumor phantom & 62.26 & 1.01 \\
\hline
\end{tabular}

Table 8. Applicator amplitude and phase settings for measurement

\begin{tabular}{c|c|c|c}
\hline $\begin{array}{c}\text { Applicator } \\
\text { number }\end{array}$ & $\begin{array}{c}\text { Amplitude } \\
{[-]}\end{array}$ & $\begin{array}{c}\text { Phase } \\
{[\text { degrees] }}\end{array}$ & $\begin{array}{c}\text { Cable Extension } \\
{[\mathrm{cm}]}\end{array}$ \\
\hline 1 & 0.39 & 0 & 9.03 \\
\hline 2 & 1 & -56.3 & 1.84 \\
\hline 3 & 0.82 & -70.7 & 0 \\
\hline 4 & 0.55 & -6.5 & 8.20 \\
\hline
\end{tabular}

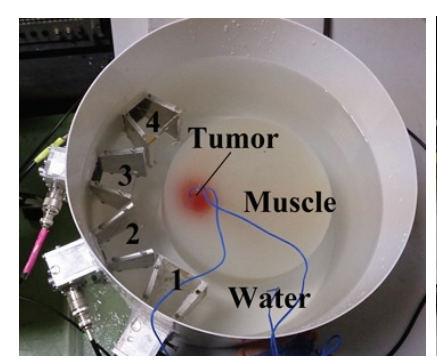

(a)

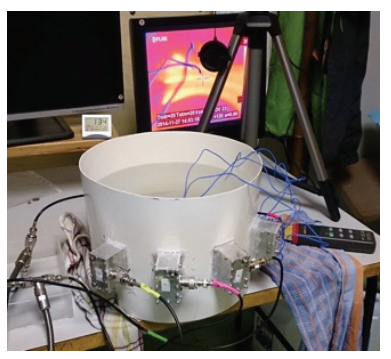

(b)
Fig. 8. Photo of the laboratory prototype, top view (a) and measurement setup (b)

\subsection{Laboratory prototype}

For the laboratory prototype production we used a special plastic container with required dimensions. The applicators at desired positions were placed at the container wall. The container and applicators are filled by deionized water. The homogenous phantom is placed into the container (see Fig. 8 (a) and (b)). For the correct phase and amplitude settings of applicators, the pre-calculated lengths of RF coaxial cables of type RG58 were used (see Table 8). Relative permittivity of dielectric material of this type of cable is 2.26 for $434 \mathrm{MHz}$.

The wavelength of coaxial cable determines the phase shift. The phase shift $2 \pi$ corresponds to $\lambda_{\text {cable }}$ that is $\sqrt{\varepsilon_{r c}}$ times lower than the vacuum wavelength (Eq. 4). 


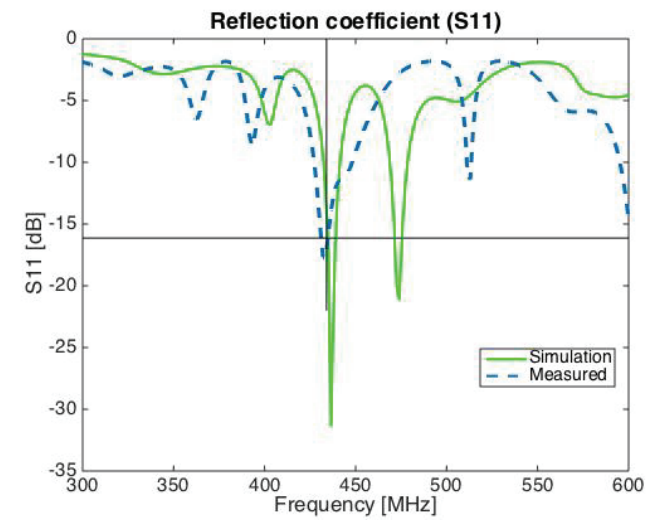

Fig. 9. Simulated and measured return loss

$$
\lambda_{\text {cable }}=\frac{c}{f \cdot \sqrt{\varepsilon_{r c}}}=\frac{299792458}{434 \cdot 10^{6} \cdot \sqrt{2.26}}=0.4598 \mathrm{~m}
$$

where

$c$ is speed of light in vacuum, $f$ is working frequency, $\varepsilon_{\mathrm{rc}}$ is relative permittivity of coaxial cable. Calculated wavelength in coaxial cable $\left(\lambda_{\text {cable }}\right)$ is $45.98 \mathrm{~cm}$.

\subsection{Experiment 1, reflection coefficient measurement}

In experiment 1 we evaluated impedance matching of each applicator separately and subsequently of the whole system. The analysis was made by vector analyzer of the Agilent E5062A type in the frequency band from 300 to $600 \mathrm{MHz}$. In the Fig. 9 there are results from this measurement (blue dashed curve) compared to results from numerical simulation (green curve). These curves represent return loss of whole system when all applicators were turned on. The main cause of differences in resonances in curve of reflection coefficient are caused by deviation in phantom dielectric parameters. The matching of the whole system is under $-10 \mathrm{~dB}$ for $434 \mathrm{MHz}$ and this is satisfactory.

\subsection{Experiment 2, temperature distribution in homogenous phantom}

In this experiment the distribution of absorbed power through temperature in a homogeneous phantom was measured. The main goal of power measurement is to verify energy focusing and heating ability of whole applicator system. SAR and temperature are related to the following relation (Eq. 5) adopted from [3]:

$$
S A R=\frac{\sigma}{2 \rho}\left|E^{2}\right|=c \cdot \frac{\Delta T}{\Delta t}
$$

where SAR is the specific absorption rate [W/kg], $\sigma$ is tissue conductivity $[\mathrm{S} / \mathrm{m}]$ at working frequency, $\rho$ is tissue density $\left[\mathrm{kg} / \mathrm{m}^{3}\right], \mathrm{E}$ is vector of electrical intensity field $[\mathrm{V} / \mathrm{m}], \mathrm{c}$ is specific heat capacity $[\mathrm{J} / \mathrm{kg} / \mathrm{K}], \mathrm{T}$ is temperature

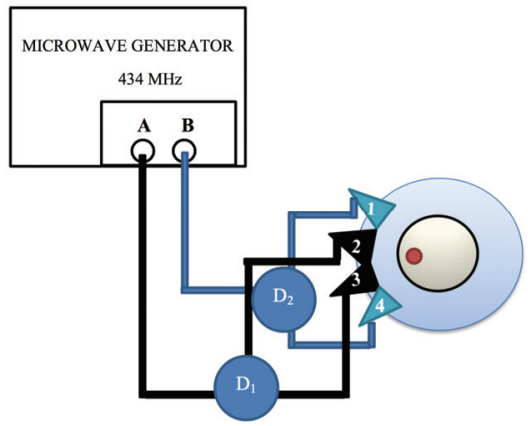

Fig. 10. Measurement setup with two power dividers

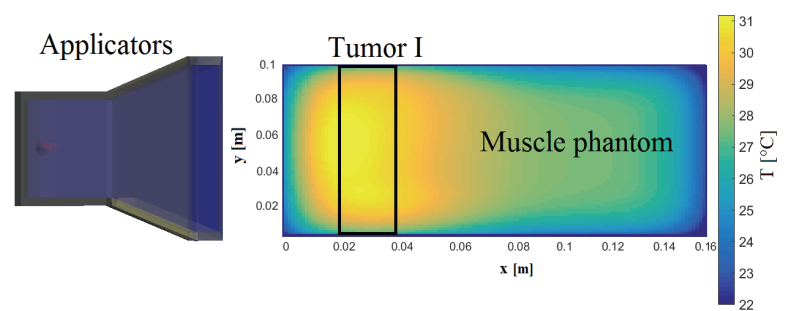

Fig. 11. Numerical simulation of temperature distribution in homogenous phantom (cross section)

$\left[{ }^{\circ} \mathrm{C}\right]$ and $\mathrm{t}$ is time [s]. The Eq. (5) is valid only for experiment of short duration, because in case of experiments with longer duration the thermal conductivity must to be involved (e.g. Penne equation).

In the Fig. 10 the measurement setup with a microwave generator and applicator system is shown. The temperature of the phantom was 22 degrees and the temperature of water bolus (deionized water) was 21 degrees. Waveguide applicators were powered by the generator "UHF-POWERGENERATOR PG 70.150.2" (it has two separated synchronized power output channels) at frequency 434 $\mathrm{MHz}$ and of total power of $150 \mathrm{~W}$ for 8 minutes. Applicators 1 and 4 were each excited by $25 \mathrm{~W}$ power (output B), applicators 2 and 3 each with power of $50 \mathrm{~W}$ (output A). In the Fig. 11 the longitudinal cross section of numerical temperature simulation through homogenous phantom is shown. The simulation settings correspond to conditions during measurement. Phantom thermograms (Fig. 12) show temperature distribution in homogenous phantoms. Energy focus is in the place where the tumor is located (black frame). Thermograms of the phantom were taken by IR camera type Flir P25.

\subsection{Results verification}

For verification of results obtained from numerical simulation, we use temperature distribution in a homogenous phantom (simulation results Fig. 11). Utilization of parameter $\mathrm{SAR}_{25}$ is inaccurate in this case, because the time of exposure was longer ( 8 minutes). For this occasion the parameter $\mathrm{T}_{41}$ was chosen. In clinical use there is an effort to increase the temperature of tumorous tissue from $37{ }^{\circ} \mathrm{C}$ to maximum $45^{\circ} \mathrm{C}$ (the temperature difference is 


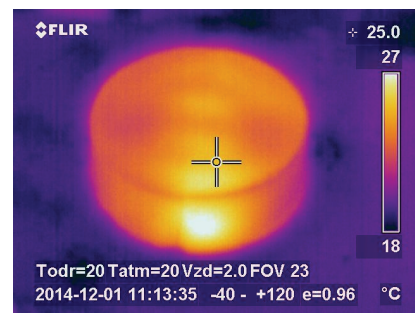

(a)

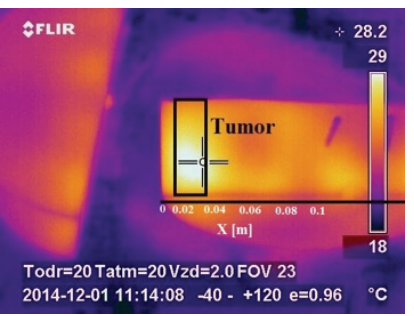

(b)
Fig. 12. Thermograms after power deposition, front view (a) and cross section (b)

$\left.8{ }^{\circ} \mathrm{C}\right)$. In our capabilities it was not possible to have a thermally tempered phantom at $37^{\circ} \mathrm{C}$ but only at $22^{\circ} \mathrm{C}$. To keep the same conditions, our maximum temperature in the phantom was $30^{\circ} \mathrm{C}$. A temperature of $26^{\circ} \mathrm{C}$ corresponds to $41^{\circ} \mathrm{C}$ used in simulations. In numerical simulation, $95 \%$ of the whole tumor volume is covered by temperature $26^{\circ} \mathrm{C}$ in this case. In the thermogram (Fig. 12 (b)) we calculated the temperature as $26^{\circ} \mathrm{C}$ for the volume cover $88 \%$. The measurement deviation from the numerical simulation is $7 \%$.

Generally speaking, temperature increased by $7-8$ degrees inside the tumor phantom in 8 minutes. This temperature increase is more than sufficient for high quality hyperthermia. Outside the tumor phantom there was a gentle increase in temperature (not greater than 3 degrees).

\section{Conclusion}

In this article we designed, evaluated and analyzed (numerically and experimentally) a new applicator system intended for focused head and neck hyperthermia therapy. First, according to our previous research, we proposed four waveguide applicator system working on frequency 434 $\mathrm{MHz}$. For evaluation of predicted SAR and temperature distribution in a phantom two volume parameters $\left(\mathrm{SAR}_{25}\right.$ and $\mathrm{T}_{41}$ ) were defined and used. Performance of the new applicator system can be also improved by the treatment planning software based on the Genetic algorithm through the distribution of SAR and temperature in the target region. The system is designed with the respect to higher sensitivity of E-field pattern to phases and amplitudes of each applicator feeding. Our simulations proved that the $\mathrm{SAR}_{25}$ is approximately by $20 \%$ higher in a treatment target due to optimization. We also observed lower risk of hotspots formation. These benefits permit energy focusing and selectively the tumor heating with the respect to healthy and sensitive tissues.

To compare our system with other methods, we made a quantitative comparison with the system of Paulides et al.. In mentioned article [6] the circular system on a numerical $3 \mathrm{D}$ human model was tested. The analysis was performed numerically (using 3D model with lymphonode and small tumor) and also by measurement. The targets are relatively similar with our Tumor II (especially in volume). Optimized results in [6] show that the lymphonode and tumor $\mathrm{SAR}_{25}$ coverage is approximately $85 \%$. With our presented system we reached $\mathrm{SAR}_{25}$ coverage for Tumor II of $80 \%$. From this comparison it is clear that our system has similar results as like other systems.

The originality of our approach is based on the fact that our applicator system uses a limited number of applicators only. This solution, of course, reduces complexity of the whole system, cost of components and it is easier to utilize it in therapy (with lower risk of unwanted hotspots).

A disadvantage of this system, which we recognize, is fixed attachment to patient's body. This is, of course, reducing the patient's comfort. Next problem is higher energy absorption on the body surface. The main solution helping us to improve temperature distribution and decreasing absorption on patient surface depends on the water bolus temperature. By the water bolus temperature decreasing we were able to supply greater energy to the target without hotspot creating on the body surface. Respecting the penetration depth and the reflection coefficient the ideal water bolus temperature is between 20 $-30{ }^{\circ} \mathrm{C}$.

For experimental results verification the laboratory prototype was constructed. The reflection coefficient of four waveguide applicators and temperature distribution was measured.

\section{Acknowledgements}

This work has been supported by COST Action TD1301, MiMed as well as by the Czech Technical University in Prague by student's project SGS 2015, with number SGS14/189/OHK3/3T/13: "Interactions of EM field with biological systems and their applications in medicine.".

\section{References}

[1] A. Argiris, M. V. Karamouzis, D. Raben, and R. L. Ferris, "Head and neck cancer," The Lancet, vol. 371, no. 9625, pp. 1695-1709, May 2008.

[2] L. P. Kowalski, "Head and neck cancer," BMC Proceedings, vol. 7, no. Suppl 2, p. K12, Apr. 2013.

[3] J. Vrba, "Medical Applications of Microwaves" (In Czech), 1st ed., CTU in Prague, Czech Republic, 2003.

[4] J. van der Zee, D. González, G. C. van Rhoon, J. D. van Dijk, W. L. van Putten, and A. A. Hart, "Comparison of radiotherapy alone with radiotherapy plus hyperthermia in locally advanced pelvic tumours: a prospective, randomised, multicentre trial," The Lancet, vol. 355, no. 9210, pp. 1119-1125, Apr. 2000.

[5] R. Colombo, L. F. Do Pozzo, A. Salonia, P. Rigatti, 
Z. Leib, J. Baniel, E. Caldarera, and M. PavoneMacaluso, "Multicentric study comparing intravesical chemotherapy alone and with local microwave hyperthermia for prophylaxis of recurrence of superficial transitional cell carcinoma," J. Clin. Oncol., vol. 21 , no. 23, pp. 4270-4276, Dec. 2003.

[6] M. M. Paulides, J. F. Bakker, E. Neufeld, J. van der Zee, P. P. Jansen, P. C. Levendag, and G. C. van Rhoon, "The HYPERcollar: A novel applicator for hyperthermia in the head and neck.," International Journal of Hyperthermia, vol. 23, no. 7, pp. 567-576, Nov. 2007.

[7] M. M. Paulides, J. F. Bakker, M. Linthorst, J. van der Zee, Z. Rijnen, E. Neufeld, P. M. T. Pattynama, P. P. Jansen, P. C. Levendag, and G. C. van Rhoon, "The clinical feasibility of deep hyperthermia treatment in the head and neck: new challenges for positioning and temperature measurement," Physics in Medicine and Biology, vol. 55, no. 9, pp. 2465-2480, May 2010.

[8] P. Wust, M. Seebass, J. Nadobny, P. Deuflhard, G. Mönicrh, and R. Felix, "Simulation studies promote technological development of radiofrequency phased array hyperthermia," International Journal of Hyperthermia, vol. 25, no. 7, pp. 517-528, Nov. 2009.

[9] J. Vrba, "Evanescent mode applicators for subcutaneous hyperthermia," Biomedical Engineering, IEEE Transactions on, vol. 40, no. 5, pp. 397-407, 1993.

[10] B. Vrbova, J. Vrba, "Microwave thermotherapy in cancer treatment: Evaluation of homogeneity of sar distribution," Progress in Electromag-netics ResearchPIER, vol. 129, pp. 181-195, 2012.

[11] A. Boag, Y. Leviatan, and A. Boag, "Analysis and optimization of waveguide multiapplicator hyperthermia systems," IEEE Transactions on Biomedical Engineering, vol. 40, no. 9, pp. 946-952, 1993.

[12] M. M. Paulides, J. F. Bakker, L. W. Hofstetter, W. C. M. Numan, R. Pellicer, E. W. Fiveland, M. Tarasek, G. C. Houston, G. C. van Rhoon, D. T. B. Yeo, and G. Kotek, "Laboratory prototype for experimental validation of MR-guided radiofrequency head and neck hyperthermia," Phys Med Biol, vol. 59, no. 9, pp. 2139-2154, May 2014.

[13] S. Kahng, K. Kahng, I. Yang, and T. Park, "A Metamaterial-Based Handset Antenna with the SAR Reduction”, J. Electr. Eng. Technol., vol. 9, no. 2, pp. 622-627, Mar. 2014.

[14] H. D. Trefná, J. Vrba, and M. Persson, "Timereversal focusing in microwave hyperthermia for deep-seated tumors," Physics in Medicine and Biology, vol. 55, no. 8, pp. 2167-2185, Apr. 2010.

[15] O. Fiser, J. Vrba, "Oriented Array of Waveguide Applicators for Local Thermotherapy", in 8th European Conference on Antennas and Propagation, 2014. EuCAP 2014, 2014, pp. 2169-2172, 2014

[16] O. Fiser, I. Merunka, L. Vojáčková, J. Vrba, Utilization of Waveguide Applicators Combination for
Electromagntic Field Focusing, In 24th International Conference Radioelektronika 2014. Bratislava: Slovak University of Technology, 2014.

[17] O. Fiser, I. Merunka, L. Vojackova, J. Vrba, „Space Distribution of SAR and Temperature in Human Model with Tumor Using Waveguide Applicator Array, In European Microwave Week 2014 Conference Proceedings. London: Horizon House Publications, 2014, p. 484-487, 2014.

[18] P. Hasgall, E. Neufeld, M. Gosselin, A. Klingenböck, and N. Kuster. (2011) IT'IS database for thermal and electromagnetic parameters of biological tissues. [Online]. Available: www.itis.ethz.ch/database

[19] B. Vrbova, P. Novakova, M. Halfarova, J. Vrba, „Planning of head and neck tumours treatment", in 29th Annual Meeting of the European Society for Hypertermic Oncology, 2014. ESHO 2014, 2014, pp. 32-33

[20] SPEAG AG, SEMCAD X Reference Guide. [Online]. Available: http://download.speag.com/releases/ semcad/1485/documentation/SEMCAD-X-Manual.pdf

[21] C. Boutelier, L. Bougues, and J. Timbal, "Experimental study of convective heat transfer coefficient for the human body in water," J Appl Physiol Respir Environ Exerc Physiol, vol. 42, no. 1, pp. 93-100, Jan 1977.

[22] R. Ortega-Palacios, L. Leija, A. Vera, and M. F. J. Cepeda, "Measurement of breast-tumor phantom dielectric properties for microwave breast cancer treatment evaluation," 2010, pp. 216-219.

[23] R. Zajicek, L. Oppl, J. Vrba, "Broadband measurement of complex permittivity using reflection method and coaxial probes", Radioengineering, vol. 17, pp 14-19, 2008

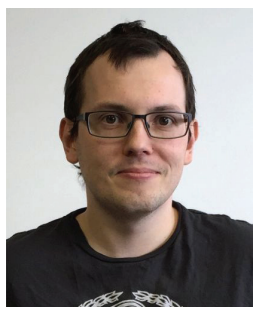

Ondrej Fiser received his B.S. and M.S. degree from Czech Technical University in Prague, 2011 and 2013 respectively. At present, he is a $\mathrm{Ph} . \mathrm{D}$ student at Department of Electromagnetic Field (CTU in Prague). His main research interests include micro-wave hyperthermia and microwave imaging.

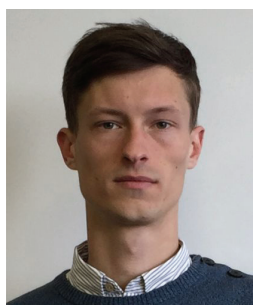

Ilja Merunka received the B.S. and M.S. degree in biomedical engineering from the Czech Technical University in Prague. He is working towards Ph.D. degree in radioelectronics at Department of Electromagnetic Field (CTU in Prague). His research interests include microwave hyperthermia, microwave tomography and numerical simulations. 


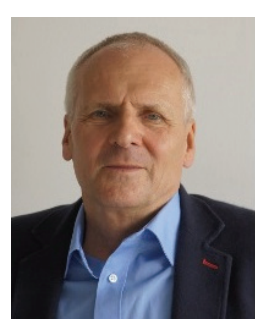

Jan Vrba received the M.Sc. and Ph.D. degrees from the CTU in Prague (1972 resp. 1976) and since 1993 he is a Full Professor of Radioelectronics at the Dept. of Electromagnetic Field, CTU in Prague. In the period 1972 till 1981 his research was oriented on parametric amplifiers and microstrip resonators. Since 1981 his research activities are focused on medical and industrial applications of microwave technology. He was a member of the team which developed the first system for microwave hyperthermia in cancer treatment in the former Czechoslovakia. He is a member of IEEE, ESHO (European Society for Hyperthermic Oncology) and Electromagnetic Academy. He was awarded by ESHO-Pyrexar Award in 2015. 